\title{
The phosphodiesterase 5 inhibitor tadalafil regulates lipidic homeostasis in human skeletal muscle cell metabolism
}

\author{
F. Marampon ${ }^{1}$ - C. Antinozzi ${ }^{1}$ - C. Corinaldesi ${ }^{1,2}$ - G. B. Vannelli ${ }^{3}$ E. Sarchielli ${ }^{3}$. \\ S. Migliaccio ${ }^{1}$ L. Di Luigi ${ }^{1}$ A. Lenzi ${ }^{4}$ C. Crescioli ${ }^{1}$
}

Received: 11 March 2017 / Accepted: 20 July 2017

(C) Springer Science+Business Media, LLC 2017

\begin{abstract}
Purpose Tadalafil seems to ameliorate insulin resistance and glucose homeostasis in humans. We have previously reported that tadalafil targets human skeletal muscle cells with an insulin (I)-like effect. We aim to evaluate in human fetal skeletal muscle cells after tadalafil or I: (i) expression profile of I-regulated genes dedicated to cellular energy control, glycolitic activity or microtubule formation/vesicle transport, as GLUT4, PPAR, HK2, IRS-1, KIFIC, and KIFAP3; (ii) GLUT4, Flotillin-1, and Caveolin-1 localization, all proteins involved in energy-dependent cell trafficking; (iii) activation of I-targeted paths, as IRS-1, PKB/ AKT, mTOR, P70/S6K. Free fatty acids intracellular level was measured. Sildenafil or a cGMP synthetic analog were used for comparison; PDE5 and PDE11 gene expression was evaluated in human fetal skeletal muscle cells.
\end{abstract}

Electronic supplementary material The online version of this article (doi:10.1007/s12020-017-1378-2) contains supplementary material, which is available to authorized users.

F. Marampon and C. Antinozzi contributed equally to this work.

C. Crescioli

clara.crescioli@uniroma4.it

1 Department of Movement, Human and Health Sciences, Università di Roma "Foro Italico", Rome, Italy

2 Leeds Institute of Rheumatic and Musculoskeletal Medicine, University of Leeds, Leeds, UK

3 Department of Experimental and Clinical Medicine, University of Florence, Florence, Italy

4 Department of Experimental Medicine, "Sapienza" University of Rome, Rome, Italy
Methods RTq-PCR, PCR, western blot, free fatty acid assay commercial kit, and lipid stain non-fluorescent assay were used.

Results Tadalafil upregulated I-targeted investigated genes with the same temporal pattern as I (GLUT4, PPAR , and IRS-1 at $3 \mathrm{~h}$; HK2, KIF1C, KIFAP3 at $12 \mathrm{~h}$ ), re-localized GLUT4 in cell sites positively immune-decorated for Caveolin-1 and Flotillin-1, suggesting the involvement of lipid rafts, induced specific residue phosphorylation of IRS$1 / \mathrm{AKT} / \mathrm{mTOR}$ complex in association with free fatty acid de novo synthesis. Sildenafil or GMP analog did not affect GLUT4 trafficking or free fatty acid levels.

Conclusion In human fetal skeletal muscle cells tadalafil likely favors energy storage by modulating lipid homeostasis via IRS-1-mediated mechanisms, involving activation of I-targeted genes and intracellular cascade related to metabolic control. Those data provide some biomolecular evidences explaining, in part, tadalafil-induced favorable control of human metabolism shown by clinical studies.

Keywords PDE5i $\cdot$ Tadalafil $\cdot$ Insulin $\cdot$ Skeletal muscle $\cdot$ Metabolism

\section{Introduction}

Phosphodiesterase type 5 inhibitors (PDE5i), including avanafil, lodenafil, mirodenafil, sildenafil, tadalafil, vardenafil, udenafil, zaprinast, icariin and its synthetic derivatives, benzamidenafil, and dasantafil, have found their widest clinical application to treat erectile dysfunction (ED), due to their effective vasodilatory action [1-3].

Tadalafil and sildenafil have been proven not only to be safe in diabetic men experiencing ED [4-7] but also to 
directly control metabolism regulation, as insulin resistance (IR) or type 2 diabetes (T2D) that tend to ameliorate after PDE5 specific inhibition [8-13].

While, at first, indirect effects - mainly based on nitric oxide (NO) release by endothelial cells - have been invoked to explain PDE5i-induced control of metabolism [6, 14], later in vivo and in vitro evidences showed direct actions of PDE5i onto metabolic processes at muscular level [15-18].

Physical exercise improves general health [19-21] and in this context, skeletal muscle, accounting for about $85 \%$ of whole-body, plays a key role as insulin (I)-stimulated glucose disposal and metabolic balance [22].

We have previously reported that tadalafil directly targets human skeletal muscle cells with an I-like effect, activating part of energy-dedicated cellular machinery [17].

Herein, we aim to further investigate whether tadalafil can modulate: the expression of some specific genes classically I-targeted; the intracellular trafficking of glucose transporter type 4 (GLUT4), the main glucose transporter at muscular level; part of the intracellular cascade specifically dedicated to I-driven energy management.

To this purpose, human fetal skeletal muscle cells (Hfsmc) a reliable cell system previously assessed [23, 24] - were analyzed after exposure to tadalafil vs. I for: time-dependent mRNA expression specific for GLUT4, peroxisome proliferator-activated receptor gamma $(P P A R \gamma)$, hexokinase 2 (HK2), insulin receptor substrate 1 (IRS-1), kinesin family member 1C (KIFlc), and kinesin-associated protein 3 (KIFAP3), all I-responsive genes engaged in different cell metabolic functions [25-29]; protein localization of GLUT4, along with Flotillin-1 (FLOT1) and Caveolin-1 (CAV1), inducible and structural intracellular protein components, respectively, involved in cell membrane reorganization/vesicle formation in glucose-dependent trafficking; intracellular activation of IRS-1, protein kinase B (PKB or AKT), mammalian target of rapamycin (mTOR), P70/S6 kinase (P70/S6K) and GSK3 $\beta$, all paths engaged in I-driven metabolic response; intracellular free fatty acids (ffa) content. Since tadalfil exhibits a potent inhibitory activity onto PDE11, its expression was investigated in Hfsmc in comparison with PDE5.

In order to determine the possible selectivity of tadalfil effect, some experiments were performed in comparison with the PDE5i sildenafil or the cGMP analog 8Bromoguanosine 3',5'-cyclic monophosphate sodium salt (8-br-cGMP).

\section{Materials and methods}

\section{Chemicals}

Tadalafil powder (100\% pure) was provided by ELI Lilly ICOS Corporation (Indianapolis, USA). Dulbecco modified eagle medium (DMEM)/Ham's F-12 medium (1:1) with and without phenol red, phosphate buffered saline (PBS) $\mathrm{Ca}^{2+} / \mathrm{Mg}^{2+}$-free, bovine serum albumin (BSA) fraction V, glutamine, antibiotics, collagenase type IV, EDTA-trypsin solution, $\mathrm{NaOH}$, Bradford Reagent, 4',6-Diamidino-2-phenylindole (DAPI), Paraformaldehyde (PFA), Triton ${ }^{\mathrm{TM}} \mathrm{X}$ (TX)-100, I, PDE5 inhibitor sildenafil citrate salt, 8-br-cGMP all reagents for western blot, polymerase chain reaction (PCR) and gel electrophoresis of PCR products were from Sigma Aldrich Corp. (St. Louis, MO, USA). Fetal bovine serum (FBS) was from HyClone (Logan, UT, USA). 2-mercaptoethanol and SYBR $^{\circledR}$ Green PCR Master Mix for qPCR were from Life Technologies, Inc. Laboratories (Grand Island, NY). Antibodies (Abs) for western blot and immunocytochemical analysis: anti-phospho-Ser-2481-mammalian target of rapamycin (p-mTOR ${ }^{\text {Ser2441 }}$ ) (SC-293132M), anti-phospho-Ser-473-protein kinase B 1/2/3 (p-AKT1/2/3 ${ }^{\text {Ser473})}$ (SC-7985), anti-phospho-Tyr-632-Insulin receptor substrate 1 (p-IRS $^{\text {Tyr632 }}$ ) (SC-17196), AKT (SC-1618), IRS (SC-559), FLOT1 (SC-25506), $\beta$-ACTIN (SC-47778) were from Santa Cruz (CA, USA), anti-phospho-Ser-2448mTOR (p-mTOR ${ }^{\text {Ser2448 }}$ ) (2971), anti-phospho-Ser-21/9 Glycogen Synthase Kinase 3- $\beta$ (p-GSK3- $\beta$ ) (9331), antiGlycogen Synthase Kinase $3-\beta$ (9315) were from Cell Signaling (MA, USA), anti-CAV1 (Ab2910), GLUT4 FITC conjugated (Ab65297), and anti-c-Myc (Ab17356) were from Abcam (Cambridge, UK). FITC-labeled and Cy3-labeled secondary antibody were from Jackson Laboratory (Maine, USA). Plastic ware for cell cultures and disposable filtration units for growth media preparation were purchased from Corning (Milan, Italy).

\section{Cell cultures}

Hfsmc were obtained as previously described [23, 24]. Briefly cells were isolated from 11 fetal skeletal male muscles (four upper and seven lower limbs) obtained after voluntary abortion (10-12 weeks of gestation). Legal abortions were performed in authorized hospital and written consent was given by the patients for human fetal tissue to be stored and used for research. The use of human fetal tissue for research purposes was approved by the Committee for investigation in humans of the Azienda Ospedaliero-Universitaria Careggi, Florence, Italy (protocol $n \circ$ 6783-04). All samples have been handled in the same way and maintained in ice-cold PBS until processed for culture preparation as described elsewhere [30]. Confluent cell cultures were split into a 1:2-1:4 ratio using EDTA-trypsin solution $(0.2-0.5 \%)$, and used from 5 th to 12th passage $(5 p-12 p)$. LNCaP clone FGC $\left(\right.$ ATCC $^{\circledR}$ CRL$1740^{\mathrm{TM}}$ ) was purchased from ATCC. Cell cultures in DMEM/Ham's F-12 or RPMI-1640 supplemented with $10 \%$ 
heat inactivated FBS, $2 \mathrm{mM}$ glutamine, $100 \mathrm{U} / \mathrm{ml}$ penicillin, and $100 \mu \mathrm{g} / \mathrm{ml}$ streptomycin were maintained in a fully humidified atmosphere of $95 \%$ air and $5 \% \mathrm{CO}_{2}$.

\section{RNA Extraction, Reverse Transcription Real-Time Quantitative PCR and semi-quantitive PCR}

For mRNA analysis: 35,000 Hfsmc were seeded in 35-mm culture dishes and maintained for $24 \mathrm{~h}$ in their growth medium; after $12 \mathrm{~h}$ of starvation (medium without serum and without phenol red), cells were stimulated for $24 \mathrm{~h}$ with tadalafil $(0.5 \mu \mathrm{M})$ and $\mathrm{I}(100 \mathrm{nM})$ for $24 \mathrm{~h}$ in serum-free medium containing $0.1 \% \mathrm{BSA}$ in serum-free medium with $0.1 \%$ BSA, cells in serum-free medium containing $0.1 \%$ BSA and vehicle were used as control. Total RNA was extracted from cultured cells using TRIzol ${ }^{\circledR}$ RNA Isolation Reagents (Ambion ${ }^{\mathrm{TM}}$ ) according to the manufacturer's instructions. Single-stranded cDNA was obtained by reverse transcription of $1 \mu \mathrm{g}$ of total RNA.

RT-qPCRs were performed using 7500 Real Time System (Applied Biosystems ${ }^{\circledR}$ ) with SYBR-green fluorophore; $40 \mathrm{ng}$ of cDNA were used as template and cycling parameters were $95^{\circ} \mathrm{C}$ for $10 \mathrm{~min}$, followed by 40 cycles of $15 \mathrm{~s}$ at $95^{\circ} \mathrm{C}, 1 \mathrm{~min}$ at $60^{\circ} \mathrm{C}, 30 \mathrm{~s}$ at $95^{\circ} \mathrm{C}, 15 \mathrm{~s}$ at $60^{\circ} \mathrm{C}$. Fluorescence intensities were analyzed using the manufacturer's software (7500 Software v2.05) and relative amounts were obtained using the $2^{-\Delta \Delta C} t$ method and normalized for the $B$ actin. Data are expressed as fold increase vs. control taken as 1. Primers for GLUT4: Fw CACCCTCACCACCC TCTG, Rev CTTTTCCTTCCAAGCCACTG; for $\beta$-actin: Fw CTGAACCCCAAGGCCAAC, Rev AGCCTGGATAG CAACGTACA; for PPAR $\gamma$ : Fw GCAATCAAAGTGGAG CCTGC, Rev TCTCCGGAAGAAACCCTTGC; for IRS-1: Fw TTCGGTACATCCTCGACGGC, Rev TGATGAACA TCAGGCGCTGT; for KIFIC: Fw ACAACGTGTGTGCA TCTTTGCC, Rev TCGTACCCGCTCACAGTAGA; for HK2: Fw ATGGAGAAAGGGCTTGGAGC, Rev CCAAA GCACACGGAAGTTGG; for KIFAP3: Fw CGGGGTTCT GCTTTGATCCT, Rev AGGACCCTTGCTAATGCACC.

Semiquantitative PCR for PDE5 and PDE11 were performed by using primers and conditions already described by Aversa A. et al. [31].

\section{Immunofluorescence analysis}

For immunofluorescence analysis, $10^{4}$ cells were seeded onto glass cover slips in growth medium and maintained for $24 \mathrm{~h}$ in serum-free medium. For GLUT4, FLOT1, and CAV1 cells were stimulated for $30 \mathrm{~min}$ with tadalafil $(0.5 \mu \mathrm{M})$, I $(100 \mathrm{nM})$, sildenafil $(1 \mu \mathrm{M})$ and 8 -br-cGMP $(10 \mu \mathrm{M})$ in serum-free medium containing $0.1 \%$ BSA. Cells in serumfree medium with $0.1 \%$ BSA and vehicle were used as control. To evaluate GLUT4 translocation, cells were fixed with $4 \%$ PFA at room temperature and incubated with blocking buffer containing $1 \%$ BSA for $30 \mathrm{~min}$ at room temperature. Ab GLUT4 (1:100) was incubated overnight, followed by $\mathrm{Cy} 3$ conjugated secondary $\mathrm{Ab}$ (1:400).

To evaluate GLUT4, FLOT1, and CAV1 localization, cells were fixed with $4 \%$ PFA at room temperature, permeabilized with $1 \%$ TX-100 for 10 min and incubated with blocking buffer containing 1\% BSA and 1\% TX-100 for $30 \mathrm{~min}$ at room temperature. Ab GLUT4 FITC-conjugated (1:40), FLOT1 (1:200) and CAV1 (1:200) were incubated overnight followed by $\mathrm{Cy} 3$ conjugated secondary $\mathrm{Ab}$ (1:400). For method specificity, slides lacking the primary Abs were processed. DAPI was used to stain nuclei (1:10000). Images were acquired at $60 \times$ magnification. Slides were examined with Zeiss Z1 microscope and Leica TCS SP2 (Leica, Milano, Italy). Experiments were performed three times with different cell preparations. For quantification, the percentage of GLUT4 positive cells was calculated by counting the number of stained cells over the total in at least 10 separate fields per slide. Experiments were performed three times with different cell preparations.

\section{Protein analysis by western blot}

For western blot analysis, Hfsmc, seeded and maintained in the same conditions as previously reported [32] were stimulated or not for the indicated times with tadalafil $(0.5 \mu \mathrm{M})$ or I $(100 \mathrm{nM})$ in serum-free medium containing $0.1 \%$ BSA. Protein concentration measurement was performed with Bradford Reagent. Protein aliquots $(20 \mu \mathrm{g})$ were processed, loaded onto SDS-PAGE and transferred on nitrocellulose membranes, according to the procedure previously described $[24,33]$. Thereafter, membranes were incubated with primary Abs diluted in Tween Tris-buffered saline (1:1000

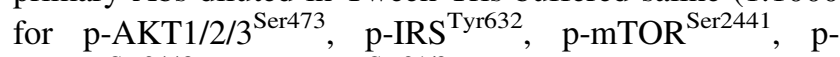
$\mathrm{mTOR}^{\mathrm{Ser} 2448}$, p-GSK3- $\beta^{\mathrm{Ser} 21 / 9}$, AKT, IRS, mTOR, and GSK3- $\beta, 1: 3000$ for $\beta$-ACTIN), followed by peroxidaseconjugated secondary IgG (1:10000). Proteins were revealed by the enhanced chemiluminescence system (ECL). Image acquisition was performed with Image Quant Las 4000 software (GE Healthcare) and densitometric analysis with Quantity One ${ }^{\circledR}$ software (Bio-Rad laboratories Inc.). Western blot analysis was performed for four/five independent experiments with different cell preparations.

\section{Bio-plex phosphoprotein assay}

Bio-Plex Phosphoprotein Assay was performed as already described [34]. Briefly, after stimulation, Hfsmc were washed with ice-cold PBS, harvested and lysed in a phosphoprotein-lysis-buffer (Bio-Rad Laboratories, Inc.). After centrifugation $\left(4500 \mathrm{~g}, 20 \mathrm{~min}, 4^{\circ} \mathrm{C}\right)$, the supernatant 
containing the phosphoprotein was collected and protein measurement performed. Ribosomal protein $\mathrm{S} 6$ kinase beta1 phosphorylation (p-P70/S6K) was measured in triplicates using the Bio-Plex protein array system (Bio-Rad Laboratories, Inc.), according to the manufacturer's protocol. The system is a multiplexed particle-based flow cytometric assay that utilizes anti-phosphokinase monoclonal antibodies linked to microspheres incorporating distinct proportions of two fluorescent dyes. Experiments were performed in triplicate with different cell preparations.

\section{Free fatty acid assays}

Intracellular total lipid amount in Hfsmc has been detected by Sudan B black staining and Abcam Quantification kit (ab65341) according to manufacturer's recommendation.

\section{Sudan B black staining}

$10^{4}$ Hfsmc were seeded onto glass coverslips in growth medium and maintained for $24 \mathrm{~h}$ in phenol-red and serumfree medium in presence or in absence of tadalafil $0.5 \mu \mathrm{M}$, sildenafil $1 \mu \mathrm{M}$ or 8-br-cGMP $10 \mu \mathrm{M}$. Cells were fixed with $1 \%$ PFA for $15 \mathrm{~min}$ at room temperature, were washed in $\mathrm{dH}_{2} \mathrm{O}$ and $70 \%$ ethanol for $2 \mathrm{~min}$ and then stained with Sudan B Black solution in 70\% ethanol for $10 \mathrm{~min}$. Stained cells were visualized by Nikon Eclipse Ti-S microscope.

\section{Abcam free fatty acid quantification kit}

$10^{6} \mathrm{Hfsmc}$ were seeded onto glass coverslips in growth medium and maintained for $24 \mathrm{~h}$ in phenol-red and serumfree medium in presence or in absence of tadalafil 0.5 and 1 $\mu \mathrm{M}$. Cells extraction and intracellular ffa quantification were performed according to manufacturer's recommendation. Experiments were performed three times with different cell preparations.

\section{Statistical analysis}

The statistical analysis was performed using GraphPad Prism 5 software (GraphPad Software, Inc., La Jolla, CA, USA) and SPSS 12.0 software package (SPSS for Windows 12.0, SPSS Inc., Chicago, IL, USA). The Kolmogorov-Smirnov test, for normal distribution of the data, one-way analysis of variance (ANOVA), $T$-test were applied. A $P$ value $<0.05$ was considered significant and corrected for comparison using the Dunnett's or Bonferroni's post hoc test, where appropriate. Data were expressed as the mean \pm standard error (SE).

\section{Results}

\section{Tadalafil upregulated I-related gene expression in Hfsme}

Time-course gene analysis showed that tadalafil $(0.5 \mu \mathrm{M})$ and I $(100 \mathrm{nM})$ significantly increased GLUT4- and IRS-1expression (Fig. 1a and b, respectively) after $12 \mathrm{~h}$; GLUT4 mRNA is higher with tadalafil $(P<0.05$ vs. I). The increase in PPAR $\gamma$ expression starting from $3 \mathrm{~h}$ after treatment with both drugs was maintained to $12 \mathrm{~h}(P<0.05$ vs. $\mathrm{c}$ and $P<$ 0.05 tadalafil vs. I). KIFIC, HK2, and KIFAP3 mRNA (Fig. 1d-f) was higher vs. c after $3 \mathrm{~h}(P<0.05$ vs. c); tadalafil induced $H K 2$ (Fig. 1e) expression greater than I $(P<0.05)$.

\section{Tadalafil promoted GLUT4 intracellular/membrane re- localization and trafficking in Hfsmc}

Permeabilized Hfsmc, treated $(30 \mathrm{~min})$ with I $(100 \mathrm{nM})$ or tadalafil $(0.5 \mu \mathrm{M})$ (Fig. 2a, panels b and c, respectively) showed higher specific signal for GLUT4 (green) as compared to control cells (c), which revealed a weak signal (Fig. 2a, panel a).

Immunodecoration for CAV1 (red) was similar in control and in cells treated with I or tadalafil (Fig. 2a, panels $\mathrm{d}-\mathrm{f})$. GLUT4 co-localized in CAV1 positive intracellular sites, as shown by merged images at higher magnification (Fig. 2a, panels $\mathrm{j}-1$ ).

Specific fluorescent signal for FLOT1 (red), almost undetectable in control cells (Fig. 2b, panel d) appeared similarly intensified after I or tadalafil (Fig. 2b, panels e and f, respectively). GLUT4 fluorescent signal (green) was confirmed to be stronger after I or tadalafil (Fig. 2b, panels b and c) than in control cells (Fig. 2b, panel a). Protein stain merging (yellow) showed GLUT4/FLOT1 cytoplasmatic co-localization after I or tadalafil (Fig. 2b panel k and l) vs. control (panel j), as shown in higher magnified pictures. Nuclei are stained with blue DAPI (Fig. 2a and b, panels g-i).

An intense (red) immunodecoration for GLUT4 was confirmed in non permeabilized Hfsmc after 30 min tadalafil or I vs. control (Figure S1, panels a-c); interestingly, GLUT4fluorescent signal was undetectable after 30 treatment with sildenafil $(1 \mu \mathrm{M})$ or 8 -br-cGMP $(10 \mu \mathrm{M})$, respectively (Figure $\mathrm{S} 1$, panels $\mathrm{d}$, e); nuclei are DAPI blue-stained (panels $\mathrm{f}-\mathrm{l}$ ), lower panels represent dye merging $(m-q)$.

Diagram below pictures depicts the percentage of GLUT4-positive stained cells, which are significantly higher only after tadalafil and I $(P<0.001$ vs. control).

\section{Tadalafil activated I-responsive cascade in Hfsmc}

The treatment of Hfsmc with tadalafil $(0.5 \mu \mathrm{M})$ or I $(100 \mathrm{nM})$ for $10 \mathrm{~min}$ significantly increased the phosphorylation of 
mTOR Ser2448 (p-mTOR ${ }^{\text {Ser2448) }}$ ) and IRS-1 Tyr632 (pIRS $^{\text {Tyr632 }}$ ) residue, as shown by densitometric analysis of western blots, expressed as ratio between phospho-protein and total-protein content $(P<0.05$ vs. control, Fig. 3a and b). Tadalafil failed to activate the phosphorylation of mTOR

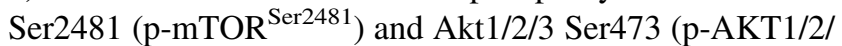
$\left.3^{\text {Ser473 }}\right)$ differently from I $(P>0.05$ vs. control, Fig. $3 c$ and d). Representative blots showing phospho-protein and totalprotein for each path analyzed are depicted below histograms. Phosphorylation of P70/S6K protein was
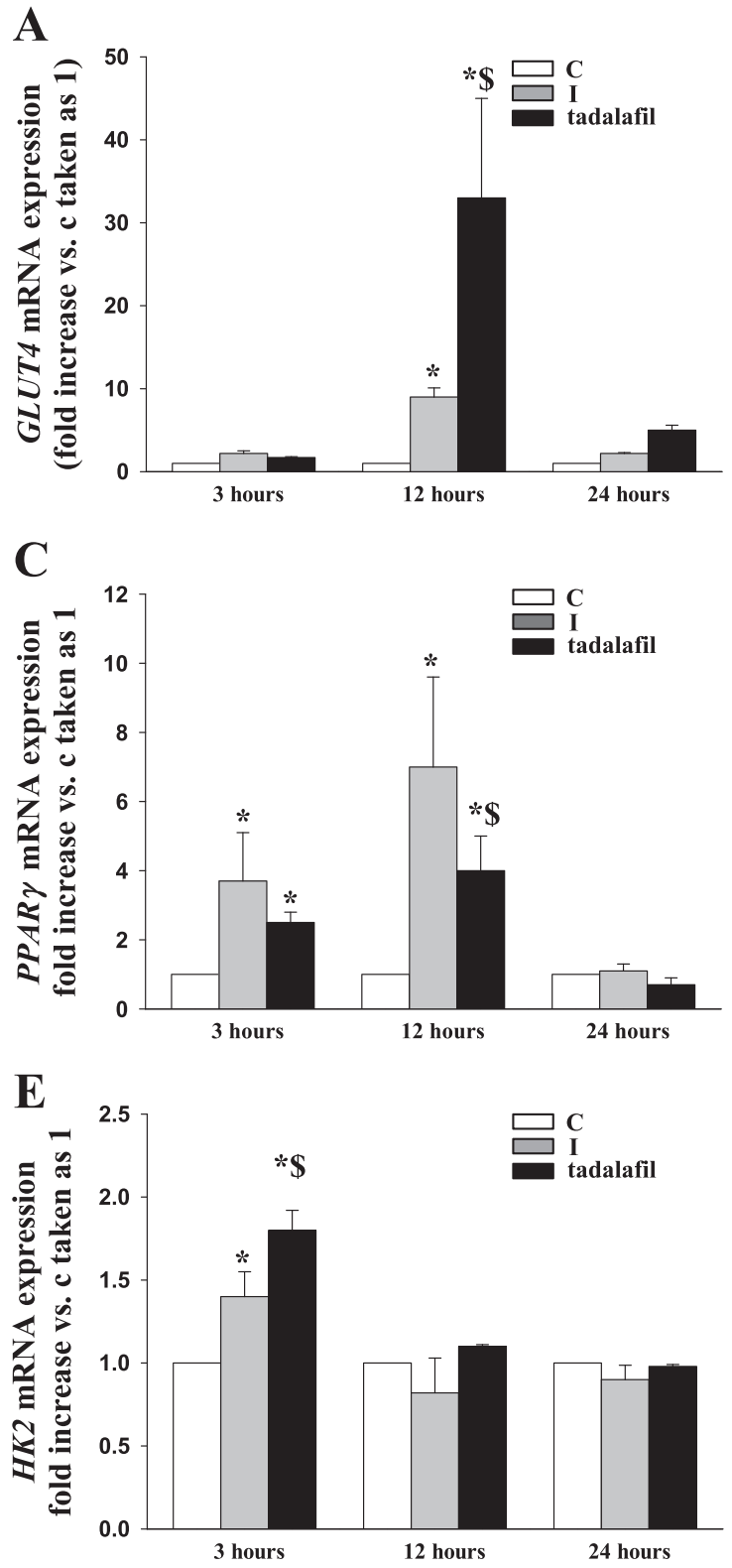

Fig. 1 Tadalafil upregulated in Hfsmc GLUT4, IRS-1, PPAR , KIF1C, $H K 2$, and KIFAP3 mRNA expression with the same temporal pattern as I. a-f Tadalafil $(0.5 \mu \mathrm{M})$ modulated GLUT4, IRS-1, PPAR, KIFIC, $H K 2$, and KIFAP3 mRNA expression with a similar temporal pattern as I (100nM). Diagrams in panels a-c show specific mRNAs of GLUT4, significantly induced only after I ( $P<0.05$ vs. control), as shown by the Bio-Plex ${ }^{\circledR}$ suspension array protein analysis system (Fig. 3e).

Since we have previously demonstrated tadalafil-induced phosphorylation/inactivation of GSK-3 $\beta$ [17], a pivotal regulator of I-dependent glucose transport in muscle [35], we analyzed GSK-3 $\beta$ phosphorylation after $10 \mathrm{~min}$ treatment with sildenafil $(1 \mu \mathrm{M})$ or 8 -br-cGMP $(10 \mu \mathrm{M})$, and found no modulation on protein activation, at variance with tadalafil (Figure S2).

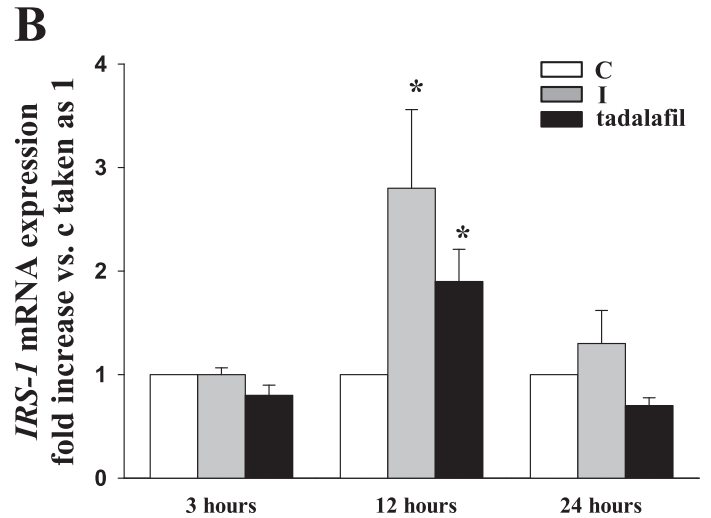

D
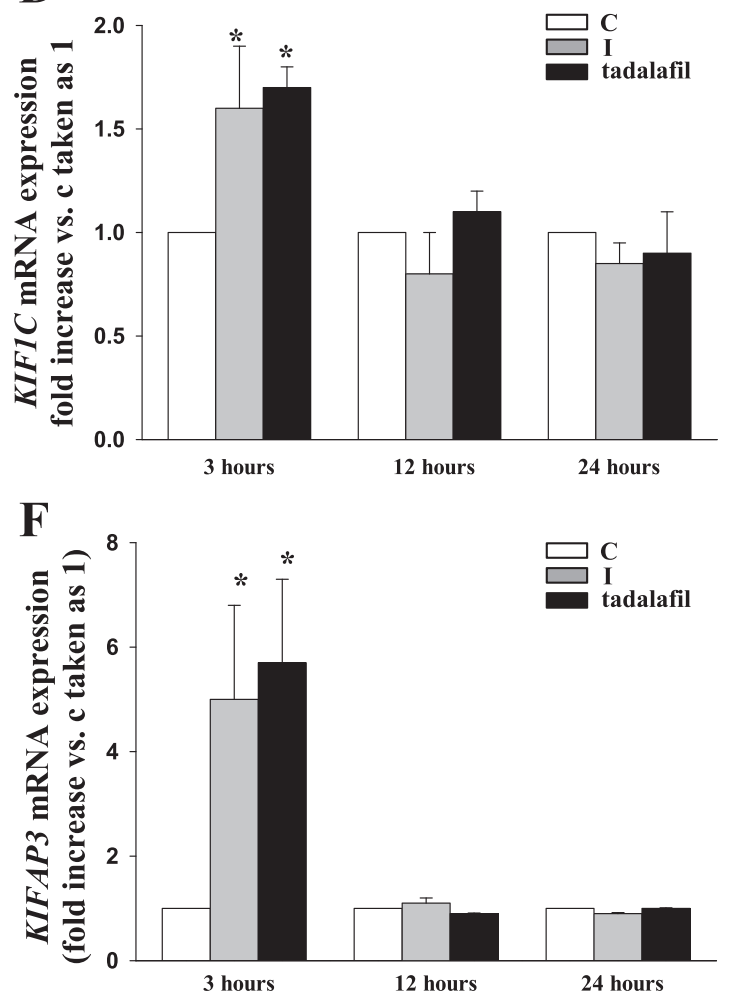

IRS-1, and PPAR $\gamma$, time-dependently upregulated with higher expression after $12 \mathrm{~h}$; panels d-f depict KIFIC, HK2, and KIFAP3 mRNA highest amount induced at $3 \mathrm{~h}\left({ }^{*} P<0.05\right.$ vs. c, ${ }^{\$} P<0.05$ vs. I). Results are derived from three experiments with different cell preparations and expressed as fold increase (mean $\pm \mathrm{SE}$ ) vs. c, taken as 1 


\section{Tadalafil induced free fatty acid synthesis in Hfsmc}

Intracellular ffa amount significantly increased after tadalafil $(0.5 \mu \mathrm{M})$ as compared with control $(P<0.05$, Fig. 4a). Cells stained with Sudan B Black (Fig. 4b) showed a significant increase of Sudan-stained spot number after tadalafil vs. control $(P<0.01)$. The treatment with sildenafil (1 $\mu \mathrm{M})$ or 8-br-cGMP $(10 \mu \mathrm{M})$ did not modify intracellular ffa amount as shown by Sudan B Black staining and intracellular positive-stained spot number (Figure S3, upper and lower panels);

\section{Hfsmc express PDE5 but not PDE11}

Hfsmc cells from upper (UpL) and lower (LwL) limb showed PDE5 but not PDE11 mRNA expression as compared to $\mathrm{LNCaP}$ prostate cancer cells ( $\mathrm{LNCaP})$, used as positive control [36] (Fig. 5).

A

C I
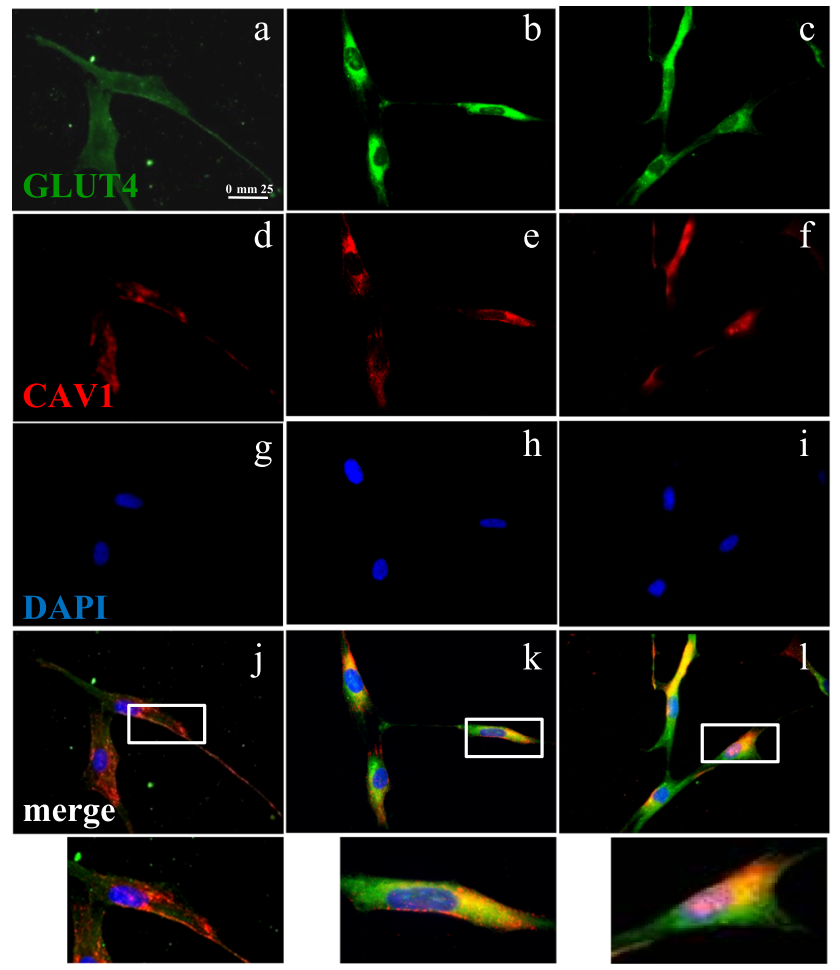

Fig. 2 Tadalafil modulated GLUT4 localization, intracellular trafficking and co-localization with FLOT1 and CAV1 in Hfsmc. a Immunofluorescence analysis in permeabilized Hfsmc show an intense immunofluorescent specific signal for GLUT4 (green) in presence of I (100 nM, panel b) or tadalafil $(0.5 \mu \mathrm{M}$, panel c) vs. respective c (panels a); immunofluorescent signal for CAV1 (red) was comparable in control and cells treated with I or tadalafil (panels $\mathbf{d}-\mathbf{f}$ ); blue nuclei are stained with DAPI (panels $\mathbf{g}-\mathbf{i})$; green/red fluorescence merging (panels $\mathbf{j}-\mathbf{l}$ ) showed

\section{Discussion}

The main finding of the study is that tadalafil controls GLUT4 membrane re-localization and intracellular trafficking, induces specific residue phosphorylation of IRS-1/ AKT/mTOR complex in association with lipid substrate regulation, as shown by ffa amount.

The large use of PDE5i for ED treatment in subjects with diabetic and cardiovascular diseases has led to the development of studies in to their extra-sexual effects.

Previous researches showed the association between PDE5 specific inhibition by sildenafil and glucose homeostasis improvement in insulin resistant high fat-fed mice $[37,38]$.

Studies in humans documented as well tadalafil-induced positive metabolic effects in insulin-resistant T2D patients [39-41], and in ED men without IR, who showed 30\% increase in insulin basal secretion after drug intake [42]. Initially, the principal mechanism describing PDE5i impact

B

C
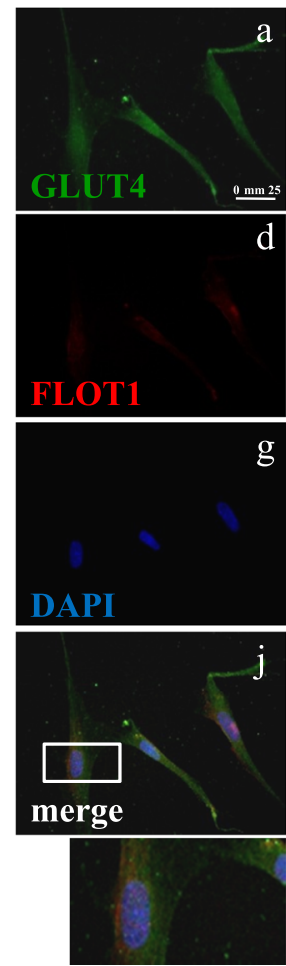

intracellular sites of GLUT4/CAV1 co-localization (yellow). b After treatment with I or tadalafil, similar higher fluorescent signal for GLUT4 (green, panels b and c) and FLOT1 (red, panels e and f) was found vs. c (panels a and $\mathbf{d}$, respectively); nuclei were stained with DAPI (panels g-i); merging (panels $\mathbf{j}-\mathbf{l}$ ) showed GLUT4/FLOT1 co-localization (yellow). Excerpts represented magnified regions of co-localization from the original images represented by the outlined area of interest indicated in the merged panels. Pictures are representative; magnification $60 \mathrm{X}$ 
A

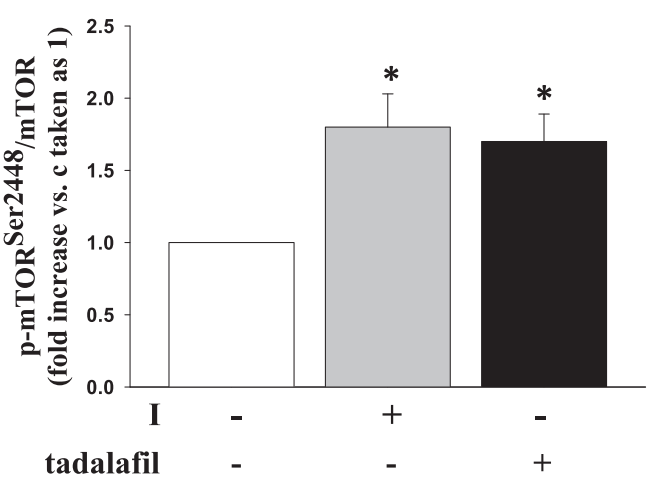

p-mTOR ${ }^{\text {Ser2448 }}$

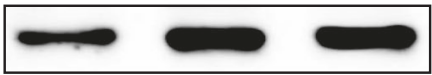

mTOR

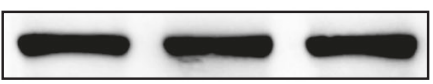

C

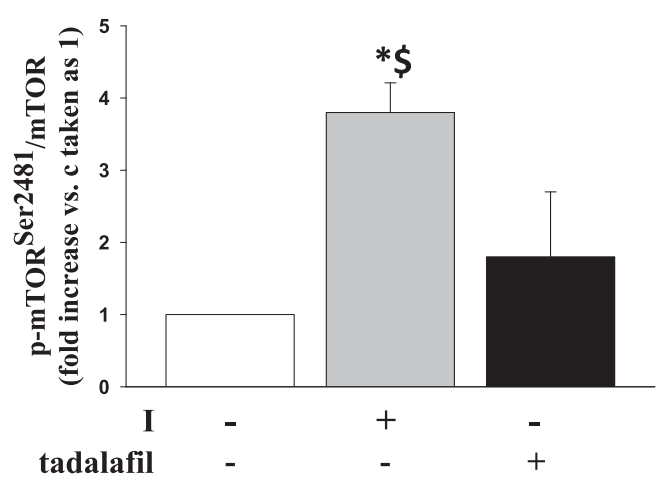

p-mTOR ${ }^{\text {Ser2481 }}$

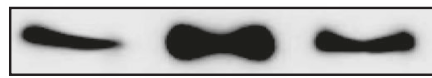

mTOR

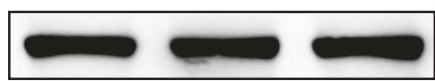

$\mathbf{E}$

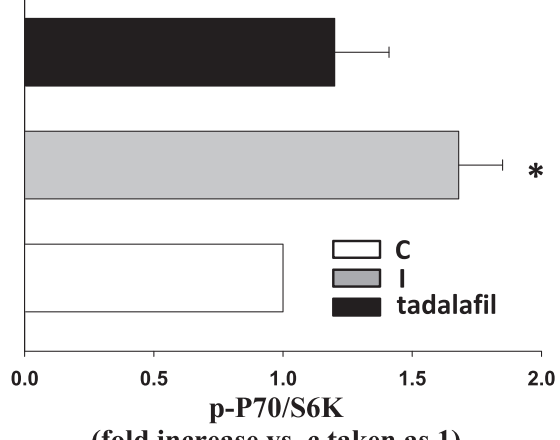

(fold increase vs. $c$ taken as 1 )

Fig. 3 Effect of tadalafil on activation of insulin-related intracellular cascade in Hfsmc. a-d Western blot analysis of p-mTOR ${ }^{\text {Ser2448 }}$ p-IRS$1^{\text {Tyr632 }}$, p-mTOR ${ }^{\text {Ser2481 }}$, and AKT ${ }^{\text {Ser473 }}$ in Hfsmc treated with I (100 nM) or tadalafil $(0.5 \mu \mathrm{M})$ for $10 \mathrm{~min}$. Upper panels a-d, show densitometric analysis and indicate a significant increase of phosphorylation level of each analyzed path ( ${ }^{*} P<0.05$ vs. c ${ }^{\$} P<0.05$ vs. tadalafil); conversely, after tadalafil a phosphorylation significantly increased only for
B

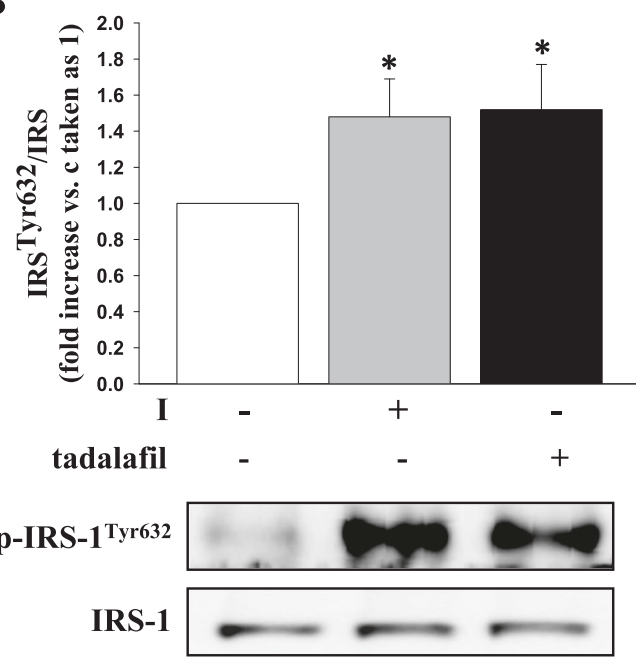

D

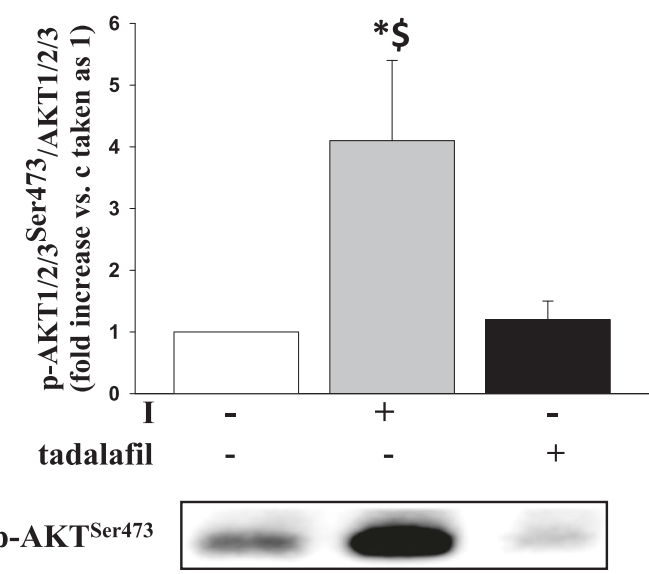

AKT

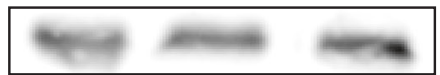

$\mathrm{mTOR}^{\text {Ser2448 }} \mathbf{a}$ and IRS- $1{ }^{\text {Ser } 473} \mathbf{b}\left({ }^{*} P<0.05\right.$ vs. c; lower panels a-d show representative western blots; total protein were used as loading controls. Densitometric analysis was calculated as ratio phosphorylated/total proteins and expressed as fold increase vs. c, taken as 1 . e Bio-Plex ${ }^{\circledR}$ suspension array system showed that $\mathrm{I}(* P<0.05)$ but not tadalafil, increased P70/S6K protein phosphorylation vs. control. Experiments were repeated three/four times and performed with two different cells preparations 


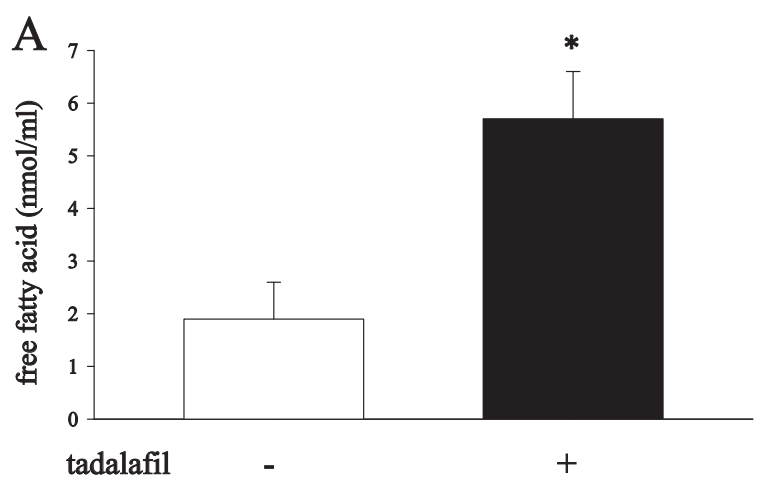

B

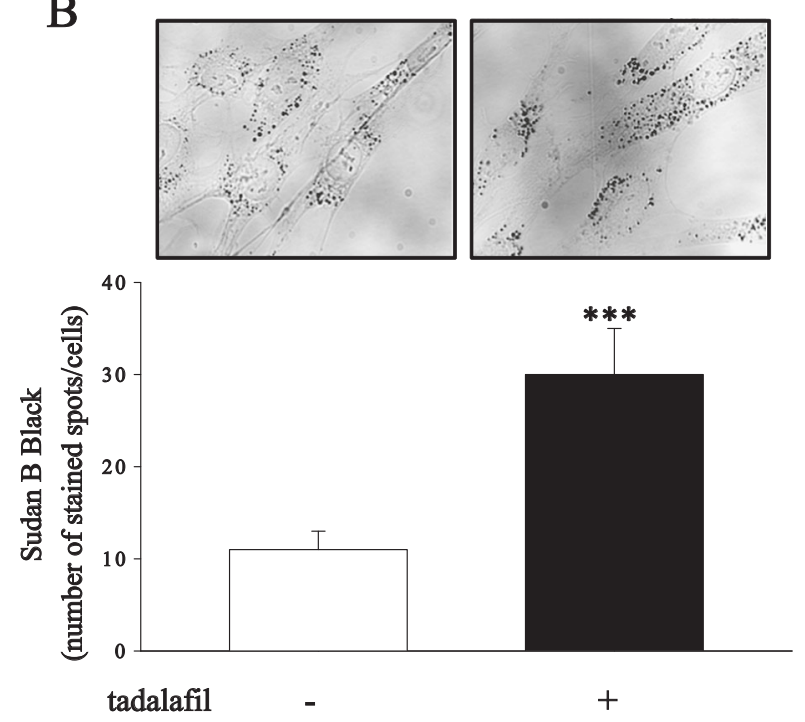

Fig. 4 Effect of tadalafil on intracellular free fatty acids amount in Hfsmc. a The treatment with tadalafil $(0.5 \mu \mathrm{M}, 24 \mathrm{~h})$ increased free fatty acid production in $\mathrm{Hfsmc}(* P<0.05)$. b Cells after tadalafil $(0.5 \mu \mathrm{M}$, $24 \mathrm{~h}$ ) showed significantly higher number of Sudan B Black-stained spots vs. c $(* * * P<0.001)$

onto metabolic processes was primarily based on indirect effect of NO, which plays a pivotal role in mediating Iinduced metabolic processes at muscular level [12, 43-45].

We have previously reported that tadalafil directly targeted Hfsmc with an I-like effect, by activating part of the energy-dedicated cell machinery [17].

This is the first study to show a similar time-dependent upregulation of I-targeted gene expression by I and tadalafil, with higher mRNA induction after $3 \mathrm{~h}$ (KIF1c, HK2, KIFAP3) or $12 \mathrm{~h}$ treatment (GLUT4, PPAR $\gamma$, IRS-1). Data from protein and intracellular trafficking analysis documented tadalafil-induced I-like mechanisms involved in energy regulation within human skeletal muscle cells. The intense specific signal for GLUT4 as observed in nonpermeabilized Hfsmc after a rapid exposure to tadalafil or I was virtually undetectable in control cells, when GLUT4 is likely masked within storage compartments [46]; neither sildenafil nor cGMP synthetic analog exert any appreciable
UpL LwL LNCaP

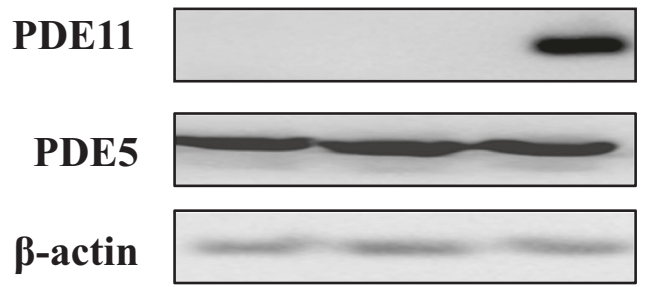

Fig. 5 Evaluation of PDE11 and PDE5 mRNA expression in Hfsmc cells. PCR shows that Hfsmc from upper (UpL) and lower (LwL) limb express PDE5 but not PDE11 mRNA. LNCaP cell line was used as positive control. $\beta$-actin was used as loading control

effect onto GLUT trafficking, suggesting a specific effect of tadalafil onto GLUT4 membrane re-localization. Moreover, tadalafil-induced GLUT4 re-localization in cell sites positively immune-decorated for CAV1 and FLOT1, as found in cells after permeabilization, suggests the involvement of specific platforms for GLUT4 internalization and trafficking, known as lipid rafts [47]. These sites are cell membrane protein assemblies which serve as platforms for a correct and coordinated GLUT4 internalization and trafficking [48-50]. While CAV1 is a "structural" protein [51-53] and similarly expressed in both control and treated cells, FLOT1 is induced during GLUT4 trafficking and appears, indeed, positively modulated in Hfsmc after tadalafil or I vs. control, as shown by the specific immunodecorated signal. Dysregulation of this biomolecular protein system in skeletal muscle cells or adipocytes is linked to diabetic phenotype, IR or T2D development [49-53]. Furthermore, we found that tadalafil rapidly phosphorylated the I-responsive intracellular complex IRS-1/AKT/mTOR. mTOR, downstream effector of IRS-1 [54] associated with AKT activation [52], is characterized by distinct complexes, mTORC1 and mTORC2; those multiprotein complexes retain different related effectors and seem to exert different biological functions activities [55]. While mTORC1 is sensitive to nutrient/nutrient depletion and involved mainly in cell growth, cell cycle, and metabolism, mTORC2 controls mostly cell survival and cytoskeleton rearrangement and seems insensitive to nutrient/energy conditions [56]. In particular, AKT phosphorylation onThr308 residue, which we have previously seen after tadalafil treatment [17], is shown to interact with TORC1, whereas AKT phosphorylation on Ser473 residue seems linked to TORC2 activity [57-59].

Our results document tadalafil-induced activation of mTOR Ser2448 residue and exclude AKT Ser473 phosphorylation and mTOR Ser2481 activation, which mirrors TORC2 engagement; conversely, tadalafil induced mTOR Ser2448 residue activation.

TORC1 phosphorylates S6K and 4EBP1 which induces protein synthesis, cell growth [60] and autophagy inhibition, as well as simultaneously repressing TORC2 function 
[59]. As from our data, S6K seems unaffected by tadalafil. Previous data similarly reported mTORC1 pathway activation independently of S6K phosphorylation [60]; this latter effect is probably due to the involvement of TORC1 differential effectors. The effect of tadalafil onto S6K needs confirmation in other experimental conditions, i.e., modifying the time of cell exposition to tadalafil or glucose concentration (from fully glucose deprivation, to mimic dietary restriction, or high glucose doses, to mimic dietary surplus); 4EBP1 phosphorylation needs to be evaluated as well.

So far, tadalafil in Hfsmc seems to activate selectively, at least in our experimental conditions, TORC1 path, engaged in energy regulation. In turn, tadalfil-induced TORC1 signaling path activation is associated with downtream GSK-3 $\beta$ inhibition in Hfsmc, as previously reported [17]. Of note, GSK3 selective inhibition is known to improve insulin-resistant skeletal muscle [35] and has been suggested as a tool for T2D control [61]. Differently from tadalafil, sildenafil and synthetic cGMP analog failed both to change GSK-3 $\beta$ status.

TORC1 activation is reported to be linked to an increase of ffa biosynthesis [62]. TORC1, indeed, regulates positively the element binding protein 1 (SREBP1) and PPAR $\gamma$ gene expression [63, 64], two transcription factors engaged in expression regulation of mRNA encoding proteins involved in lipid and cholesterol homeostasis [65, 66]. We found, indeed, a significant upregulation of mRNA specific for PPAR $\gamma 3$ and $12 \mathrm{~h}$ after tadalafil, similarly to I. After tadalafil we observed an increase of intracellular ffa amount, in line with drug-induced rise in ffa release, as previously shown in Hfsmc supernatants [17].

As we have previously hypothesized, this effect is likely the result of tadalafil-induced citrate shunt/accumulation [17], which, in Hfsmc seems to end in ffa production-as lactate release by these cells has never been observed [17].

It is well known that the ectopic lipid droplets and excess in lipid accumulation in non-adipose tissue is the main critical mechanism responsible for skeletal muscle IR development. However, lipids have been long also recognized as a metabolic fuel source for muscle activity [67, 68].

Indeed, the investigations onto mechanisms underlying fatty acid content in muscle have been framed in distinct contexts: fuel metabolic functions and IR-related lipotoxic effects [69].

While intramyocellular content is predictive of IR/diabetes risk, ffa storage as intramuscular triglycerides, conversely, seems to be a protective mechanism against IR, when ffa uptake by muscle is increased due to high lipidemic profile (i.e., following lipid-rich diet).

However, intramuscular lipid synthesis rate, rather than intramuscular concentration, has been supposed to be the critical factor related to I sensitivity [70, 71].
This observation took first place from a phenomenon termed "athlete's paradox" and observed in endurancetrained athletes, who display intramyocellular higher synthesis rate and lipid content coupled to I sensitivity enhancement vs. sedentary subjects [70]. Studies performed with isotopic tracers confirmed that intramuscular lipid is utilized as fuel source by muscle itself during exercise [72]

So far, the athlete's paradox might represent the convergence of the distinct research contexts, discriminating healthy-related or disease-related function of intramyocellular lipids, based on the novo synthesis at muscular cell level.

In this view, we could contextualize tadalafil-induced ffa synthesis in human skeletal muscle cells as a mechanism potentially related to I sensitivity; this effect seems specifically tadalafil-related, as suggested by the lack of any change in ffa intracellular amount after sildenafil or 8-brcGMP.

Understanding the significance of intramuscular lipid metabolism/production as fuel in human health is complex. Many variables should be considered when facing this topic, from lipid/ffa types, fasting or feeding conditions, sedentary or active status [73]. Our experiments were all performed in starving conditions to avoid any possible interference by other nutrients present, i.e., in serumsupplemented growth medium and ensure that the effects observed were evoked by to tadalafil; as previously addressed, further investigations modifying experimental conditions (glucose concentration, drug doses, time of treatment) are mandatory.

Based on the experimental evidence so far collected in Hfsmc, we speculate that tadalafil exerts its specific effect directly sensitizing I-responsive intracellular paths with a mechanism independent of cGMP, whose level, however, is increased after cell exposure to the drug, as previously reported [17]. In addition, neither 8-br-cGMP nor sildenafil, known to stabilize intracellular cGMP levels, targeted skeletal muscle metabolic trafficking and paths: in line with this observation, it has been shown that sildenafil failed to activate downstream I-signaling in muscle extracts of highfat fed mice, albeit controlling muscle glucose homeostasis [37].

Glucose trafficking in skeletal muscle cells, either contracting or non-contratting, might also depend on NO $[74,75]$, independently from I-responsive paths involvement [76]. Since NO is described to regulate skeletal muscle glucose homeostasis trough cGMP, we speculate that tadalafil in Hfsmc, working independently of cGMP, may not involve muscular NO. However, those mechanismsNO-driven or I-driven might occur simultaneously and independently [76]. Our future investigations, aimed to further clarify the fine-tuned biomolecular mechanisms underlying tadalafil action, include studies on NO possible 
direct effects onto muscular glucose homeostasis. In conclusion, in human skeletal muscle cells tadalafil likely favors energy storage by modulating lipid homeostasis via IRS-1-mediated mechanisms, involving direct activation of I-targeted genes and proteins. Since we have shown the presence of PDE5 but not PDE11 in Hfsmc, in line with some authors [77], the effects observed are due to tadalafilmediated PDE5 inhibition, albeit the drug is known to target PDE11 as well [78]. Those data, while providing some biomolecular evidences for an I-like effect of tadalafil in human skeletal muscle cells, explain, in part, tadalafilinduced favorable control of human metabolism shown by clinical studies and open to novel therapeutic application for PDE5i.

Acknowledgements This report was supported by ELI Lilly ICOS Corporation, Indianapolis, USA.

Funding This study was funded by ELI LILLY (Ex NCR H6D-ITV015).

\section{Compliance with ethical standards}

Conflict of interest Crescioli $\mathrm{C}$ declares that she has received research grants from Company ELI LILLY. All the other authors declare that they have no competing interests.

Ethical approval This article does not contain any studies with animals performed by any of the authors.

\section{References}

1. C.C. Carson, T.F. Lue, Phosphodiesterase type 5 inhibitors for erectile dysfunction. BJU Int. 96, 257-280 (2005)

2. J.H. Hong, Y.S. Kwon, I.Y. Kim, Pharmacodynamics, pharmacokinetics and clinical efficacy of phosphodiesterase-5 inhibitors. Exp. Opin. Drug Metab. Toxicol. 13, 183-192 (2017)

3. M. Dell'Agli, G.V. Galli, E. Dal Cero, F. Belluti, R. Matera, E. Zironi, G. Pagliuca, E. Bosisio, Potent inhibition of human phosphodiesterase-5 by icariin derivatives. J. Nat. Prod. 71, 1513-1517 (2008)

4. A. Basu, R.E. Ryder, New treatment options for erectile dysfunction in patients with diabetes mellitus. Drugs 64, 2667-2688 (2004)

5. S.H. Francis, J.D. Corbin, PDE5 inhibitors: targeting erectile dysfunction in diabetics. Curr. Opin. Pharmacol. 11, 683-688 (2011)

6. Y.P. Balhara, S. Sarkar, R. Gupta, Phosphodiesterase-5 inhibitors for erectile dysfunction in patients with diabetes mellitus: A systematic review and meta-analysis of randomized controlled trials. Indian J. Endocrinol. Metab. 19, 451-461 (2015)

7. D. Hatzichristou, M. Gambla, E. Rubio-Aurioles, J. Buvat, G.B. Brock, G. Spera, L. Rose, D. Lording, S. Liang, Efficacy of tadalafil once daily in men with diabetes mellitus and erectile dysfunction. Diabet. Med. 25, 138-46 (2008)

8. A. Aversa, Systemic and metabolic effects of PDE5-inhibitor drugs. World J. Diabetes 1, 3-7 (2010)
9. C.E. Ramirez, H. Nian, C. Yu, J.L. Gamboa, J.M. Luther, N.J. Brown, C.A. Shibao, Treatment with Sildenafil Improves Insulin Sensitivity in Prediabetes: A Randomized, Controlled Trial. J. Clin. Endocrinol. Metab. 100, 4533-4540 (2015)

10. L. Fu, F. Li, A. Bruckbauer, Q. Cao, X. Cui, R. Wu, H. Shi, B. Xue, M.B. Zemel, Interaction between leucine and phosphodiesterase 5 inhibition in modulating insulin sensitivity and lipid metabolism. Diabetes Metab. Syndr. Obes. 8, 227-239 (2015)

11. J.E. Ho, P. Arora, G.A. Walford, A. Ghorbani, D.P. Guanaga, B. P. Dhakal, D.I. Nathan, E.S. Buys, J.C. Florez, C. Newton-Cheh, G.D. Lewis, T.J. Wang, Effect of phosphodiesterase inhibition on insulin resistance in obese individuals. J. Am. Heart Assoc. (2014). doi:10.1161/JAHA.114.001001

12. L. Di Luigi, C. Baldari, P. Sgrò, G.P. Emerenziani, M.C. Gallotta, S. Bianchini, F. Romanelli, F. Pigozzi, A. Lenzi, L. Guidetti, The type 5 phosphodiesterase inhibitor tadalafil influences salivary cortisol, testosterone, and dehydroepiandrosterone sulphate responses to maximal exercise in healthy men. J. Clin. Endocrinol. Metab. (2008). doi:10.1210/jc.2008-0847

13. L. Di Luigi, C. Baldari, F. Pigozzi, G.P. Emerenziani, M.C. Gallotta, F. Iellamo, E. Ciminelli, P. Sgrò, F. Romanelli, A. Lenzi, L. Guidetti, The long-acting phosphodiesterase inhibitor tadalafil does not influence athletes' VO2max, aerobic, and anaerobic thresholds in normoxia. Int. J. Sports Med. 29, 110-115 (2008)

14. H. Duplain, R. Burcelin, C. Sartori, S. Cook, M. Egli, M. Lepori, P. Vollenweider, T. Pedrazzini, P. Nicod, B. Thorens, U. Scherrer, Insulin resistance, hyperlipidemia, and hypertension in mice lacking endothelial nitric oxide synthase. Circulation 104, 342-345 (2001)

15. M. Sheffield-Moore, J.E. Wiktorowicz, K.V. Soman, C.P. Danesi, M.P. Kinsky, E.L. Dillon, K.M. Randolph, S.L. Casperson, D.C. Gore, A.M. Horstman, J.P. Lynch, B.M. Doucet, J.A. Mettler, J. W. Ryder, L.L. Ploutz-Snyder, J.W. Hsu, F. Jahoor, K. Jennings, G.R. White, S.D. McCammon, W.J. Durham, Sildenafil increases muscle protein synthesis and reduces muscle fatigue. Clin. Transl. Sci. 6, 463-468 (2013)

16. S. Sabatini, P. Sgrò, G. Duranti, R. Ceci, L. Di Luigi, Tadalafil alters energy metabolism in $\mathrm{C} 2 \mathrm{C} 12$ skeletal muscle cells. Acta Biochim. Pol. 58, 237-241 (2011)

17. C. Crescioli, N. Sturli, M. Sottili, P. Bonini, A. Lenzi, L. Di Luigi, Insulin-like effect of the phosphodiesterase type 5 inhibitor tadalafil onto male human skeletal muscle cells. J. Endocrinol. Invest. (2013). doi:10.3275/9034

18. E. Milani, S. Nikfar, R. Khorasani, M.J. Zamani, M. Abdollahi, Reduction of diabetes-induced oxidative stress by phosphodiesterase inhibitors in rats. Comp. Biochem. Physiol. C Toxicol. Pharmacol. 140, 251-255 (2005)

19. L. Di Luigi, F. Romanelli, P. Sgrò., A. Lenzi, Andrological aspects of physical exercise and sport medicine. Endocrine 42, 278-284 (2012)

20. L. Di Luigi, Supplements and the endocrine system in athletes. Clin. Sports Med. 27, 131-151 (2008)

21. C. Baldari, L. Di Luigi, G.P. Emerenziani, M.C. Gallotta, P. Sgrò, L. Guidetti, Is explosive performance influenced by androgen concentrations in young male soccer players? Br. J. Sports Med. 43, 191-194 (2009)

22. R.A. De Fronzo, E. Jacot, E. Jequier, E. Maeder, J. Wahren, J.P. Felber, The effect of insulin on the disposal of intravenous glucose. Results from indirect calorimetry and hepatic and femoral venous catheterization. Diabetes 30, 1000-1007 (1981)

23. C. Crescioli, M. Sottili, P. Bonini, L. Cosmi, P. Chiarugi, P. Romagnani, G.B. Vannelli, M. Colletti, A.M. Isidori, M. Serio, A. Lenzi, L. Di Luigi, Inflammatory response in human skeletal muscle cells: CXCL10 as a potential therapeutic target. Eur. J. Cell Biol. 91, 139-149 (2012) 
24. C. Antinozzi, C. Corinaldesi, C. Giordano, A. Pisano, B. Cerbelli, S. Migliaccio, L. Di Luigi, K. Stefanantoni, G.B. Vannelli, S. Minisola, G. Valesini, V. Riccieri, A. Lenzi, C. Crescioli, Potential role for the VDR agonist elocalcitol in metabolic control: Evidences in human skeletal muscle cells. J. Steroid Biochem. Mol. Biol. 167, 169-181 (2017)

25. Z.W. Yu, J. Burén, S. Enerbäck, E. Nilsson, L. Samuelsson, J.W. Eriksson, Insulin can enhance GLUT4 gene expression in 3T3F442A cells and this effect is mimicked by vanadate but counteracted by cAMP and high glucose--potential implications for insulin resistance. Biochim. Biophys. Acta 1535, 174-185 (2001)

26. J. Rieusset, F. Andreelli, D. Auboeuf, M. Roques, P. Vallier, J.P. Riou, J. Auwerx, M. Laville, H. Vidal, Insulin acutely regulates the expression of the peroxisome proliferator-activated receptorgamma in human adipocytes. Diabetes 48, 699-705 (1999)

27. H. Osawa, C. Sutherland, R.B. Robey, R.L. Printz, D.K. Granner, Analysis of the signaling pathway involved in the regulation of hexokinase II gene transcription by insulin. J. Biol. Chem. 271, 16690-16694 (1996)

28. S. Rome, K. Clément, R. Rabasa-Lhoret, E. Loizon, C. Poitou, G. S. Barsh, J.P. Riou, M. Laville, H. Vidal, Microarray profiling of human skeletal muscle reveals that insulin regulates approximately 800 genes during a hyperinsulinemic clamp. J. Biol. Chem. 278, 18063-18068 (2003)

29. K.A. Cho, P.B. Kang, PLIN2 inhibits insulin-induced glucose uptake in myoblasts through the activation of the NLRP3 inflammasome. Int. J. Mol. Med. 36, 839-844 (2015)

30. P. Gallina, M. Paganini, L. Lombardini, R. Saccardi, M. Marini, M.T. De Cristofaro, P. Pinzani, F. Salvianti, C. Crescioli, A. Di Rita., S. Bucciantini, C. Mechi, E. Sarchielli, M. Moretti, S. Piacentini, G. Gritti, A. Bosi, S. Sorbi, G. Orlandini, G.B. Vannelli, N. Di Lorenzo, Development of human striatal anlagen after transplantation in a patient with Huntington's disease. Exp. Neurol. 213, 241-244 (2008)

31. A. Aversa, M. Caprio, A. Antelmi, A. Armani, M. Brama, E.A. Greco, D. Francomano, M. Calanchini, G. Spera, L. Di Luigi, G. M. Rosano, A. Lenzi, S. Migliaccio, A. Fabbri, Exposure to phosphodiesterase type 5 inhibitors stimulates aromatase expression in human adipocytes in vitro. J. Sex. Med. 8, 696-704 (2011)

32. S. Marchiani, L. Bonaccorsi, P. Ferruzzi, C. Crescioli, M. Muratori, L. Adorini, G. Forti, M. Maggi, E. Baldi, The vitamin D analogue BXL-628 inhibits growth factor-stimulated proliferation and invasion of DU145 prostate cancer cells. J. Cancer Res. Clin. Oncol. 132, 408-416 (2006)

33. G.L. Gravina, F. Marampon, P. Muzi, A. Mancini, M. Piccolella, P. Negri-Cesi, M. Motta, A. Lenzi, E. Di Cesare, V. Tombolini, E. A. Jannini, C. Festuccia, PXD101 potentiates hormonal therapy and prevents the onset of castration-resistant phenotype modulating androgen receptor, HSP90, and CRM1 in preclinical models of prostate cancer. Endocr. Relat. Cancer. (2013). doi:10. 1530/ERC-12-0240

34. L. Di Luigi, M. Sottili, C. Antinozzi, G.B. Vannelli, F. Romanelli, V. Riccieri, G. Valesini, A. Lenzi, C. Crescioli, The vitamin D receptor agonist BXL-01-0029 as a potential new pharmacological tool for the treatment of inflammatory myopathies. PLoS One. (2013). doi:10.1371/journal.pone.0077745

35. E.J. Henriksen, B.B. Dokken, Role of glycogen synthase kinase-3 in insulin resistance and type 2 diabetes. Curr Drug Targets 7, 1435-1441 (2006)

36. S. Uckert, P. Hedlund, K.E. Andersson, M.C. Truss, U. Jonas, C.G. Stief, Update on phosphodiesterase (PDE) isoenzymes as pharmacologic targets in urology: present and future. Eur Urol. 50, 1194-1207 (2006)

37. J.E. Ayala, D.P. Bracy, B.M. Julien, J.N. Rottman, P.T. Fueger, D.H. Wasserman, Chronic treatment with sildenafil improves energy balance and insulin action in high fat-fed conscious mice. Diabetes 56, 1025-1033 (2007)

38. L. Fu, F. Li, A. Bruckbauer, Q. Cao, X. Cui, R. Wu, H. Shi, B. Xue, M.B. Zemel, Interaction between leucine and phosphodiesterase 5 inhibition in modulating insulin sensitivity and lipid metabolism. Diabetes Metab. Syndr. Obes. (2015). doi:10.2147/ DMSO.S82338

39. P.A. Jansson, G. Murdolo, L. Sjögren, B. Nyström, M. Sjöstrand, L. Strindberg, P. Lönnroth, Tadalafil increases muscle capillary recruitment and forearm glucose uptake in women with type 2 diabetes. Diabetologia 53, 2205-2208 (2010)

40. L. Sjögren, J. Olausson, L. Strindberg, R. Mobini, P. Fogelstrand, L. Mattsson Hultén, P.A. Jansson, Postprandial effects of the phosphodiesterase-5 inhibitor tadalafil in people with wellcontrolled Type 2 diabetes mellitus: a randomized controlled trial. Diabet. Med. 33, 1299-1301 (2016)

41. G. Murdolo, M. Sjöstrand, L. Strindberg, P. Lönnroth, P.A. Jansson, The selective phosphodiesterase-5 inhibitor tadalafil induces microvascular and metabolic effects in type 2 diabetic postmenopausal females. J. Clin. Endocrinol. Metab. 98, 245-254 (2013)

42. C. McMahon, Efficacy and safety of daily tadalafil in men with erectile dysfunction previously unresponsive to on-demand tadalafil. J. Sex Med. 1, 292-300 (2004)

43. B.E. Sansbury, B.G. Hill, Regulation of obesity and insulin resistance by nitric oxide. Free Radic. Biol. Med. 73, 383-399 (2014)

44. U. Förstermann, T. Münzel, Endothelial nitric oxide synthase in vascular disease: from marvel to menace. Circulation 113, 1708-1714 (2006)

45. J.M. Richey, The vascular endothelium, a benign restrictive barrier? NO! Role of nitric oxide in regulating insulin action. Diabetes. (2013). doi:10.2337/db13-1395

46. M. Kanzaki, J.E. Pessin, Insulin signaling: GLUT4 vesicles exit via the exocyst. Curr. Biol. 15, 574-576 (2003)

47. J.B. Helms, C. Zurzolo, Lipids as targeting signals: lipid rafts and intracellular trafficking. Traffic 5, 247-54 (2004)

48. L.H. Chamberlain, G.W. Gould, The vesicle- and target-SNARE proteins that mediate Glut4 vesicle fusion are localized in detergent-insoluble lipid rafts present on distinct intracellular membranes. J. Biol. Chem. 277, 49750-49754 (2002)

49. A. Ros-Baro, C. Lopez-Iglesias, S. Peiro, D. Bellido, M. Palacin, A. Zorzano, M. Camps, Lipid rafts are required for GLUT4 internalization in adipose cells. Proc. Natl Acad. Sci. USA. 98, 12050-12055 (2001)

50. K. Fecchi, D. Volonte, M.P. Hezel, K. Schmeck, F. Galbiati, Spatial and temporal regulation of GLUT4 translocation by flotillin-1 and caveolin-3 in skeletal muscle cells. FASEB J. 20, 705-707 (2006)

51. E. González-Muñoz, C. López-Iglesias, M. Calvo, M. Palacín, A. Zorzano, M. Camps, Caveolin-1 loss of function accelerates glucose transporter 4 and insulin receptor degradation in 3T3-L1 adipocytes. Endocrinology 150, 3493-3502 (2009)

52. Y. Hoon Son, S.J. Lee, K.B. Lee, J.H. Lee, E.M. Jeong, S.C. Chung, S.C. Park, I.G. Kim, Dexamethasone downregulates caveolin-1 causing muscle atrophy via inhibited insulin signaling. J. Endocrinol. 225, 27-37 (2005)

53. Y.S. Oh, L.Y. Khil, K.A. Cho, S.J. Ryu, M.K. Ha, G.J. Cheon, T.S. Lee, J.W. Yoon, H.S. Jun, S.C. Park, A potential role for skeletal muscle caveolin-1 as an insulin sensitivity modulator in ageing-dependent non-obese type 2 diabetes: studies in a new mouse model. Diabetologia 51, 1025-1034 (2008)

54. M. Laplante, D.M. Sabatini, mTOR signaling in growth control and disease. Cell 149, 274-293 (2012)

55. D.A. Altomare, A.R. Khaled, Homeostasis and the importance for a balance between AKT/mTOR activity and intracellular signaling. Curr. Med. Chem. 9, 3748-3762 (2012) 
56. N. Takei, H. Nawa, mTOR signaling and its roles in normal and abnormal brain development. Front. Mol. Neurosci. (2014). doi:10.3389/fnmol.2014.00028

57. M. Gao, J. Liang, Y. Lu, H. Guo, P. German, S. Bai, E. Jonasch, X. Yang, G.B. Mills, Z. Ding, Site-specific activation of AKT protects cells from death induced by glucose deprivation. Oncogene. 33, 745-755 (2014)

58. S.F. Moore, R.W. Hunter, I. Hers, mTORC2 protein complexmediated Akt (Protein Kinase B) Serine 473 Phosphorylation is not required for Akt1 activity in human platelets. J. Biol. Chem. 286, 24553-24560 (2011)

59. L. Vadlakonda, A. Dash, M. Pasupuleti, K. Anil Kumar, P. Reddanna, The Paradox of Akt-mTOR Interactions. Front. Oncol. (2013). doi:10.3389/fonc.2013.00165

60. C.A. Moody, R.S. Scott, N. Amirghahari, C.O. Nathan, L.S. Young, C.W. Dawson, J.W. Sixbey, Modulation of the cell growth regulator mTOR by Epstein-Barr virus-encoded LMP2A. J. Virol. 79, 5499-5506 (2005)

61. C. Gao, C. Hölscher, Y. Liu, L. Li, GSK3: a key target for the development of novel treatments for type 2 diabetes mellitus and Alzheimer disease. Rev. Neurosci. 23, 1-11 (2011)

62. M. Laplante, D.M. Sabatini, mTOR signaling at a glance. J. Cell. Sci. (2009). doi:10.1242/jcs.051011

63. T. Porstmann, C.R. Santos, B. Griffiths, M. Cully, M. Wu, S. Leevers, J.R. Griffiths, Y.L. Chung, A. Schulze, SREBP activity is regulated by mTORC1 and contributes to Aktdependent cell growth. Cell Metab. 8, 224-236 (2008)

64. J.E. Kim, J. Chen, Regulation of peroxisome proliferator-activated receptor-gamma activity by mammalian target of rapamycin and amino acids in adipogenesis. Diabetes 53, 2748-2756 (2004)

65. C. Fernández-Hernando, K.J. Moore, MicroRNA modulation of cholesterol homeostasis. Arterioscler. Thromb. Vasc. Biol. 31, 2378-2382 (2011)

66. M.A. Bouhlel, B. Staels, G. Chinetti-Gbaguidi, Peroxisome proliferator-activated receptors--from active regulators of macrophage biology to pharmacological targets in the treatment of cardiovascular disease. J. Intern. Med. 263, 28-42 (2008)
67. L. Luo, M. Liu, Adipose tissue in control of metabolism. J. Endocrinol. 231, R77-R99 (2016)

68. M. Coelho, T. Oliveira, R. Fernandes, Biochemistry of adipose tissue: an endocrine organ. Arch. Med. Sci. 9, 191-200 (2013)

69. L.J. van Loon, B.H. Goodpaster, Increased intramuscular lipid storage in the insulin-resistant and endurance-trained state. Pflugers Arch. 451, 606-616 (2006)

70. B.H. Goodpaster, J. He, S. Watkins, D.E. Kelley, Skeletal muscle lipid content and insulin resistance: evidence for a paradox in endurance-trained athletes. J. Clin. Endocrinol. Metab. 86, 5755-5761 (2001)

71. A.P. Russell, Lipotoxicity: the obese and endurance-trained paradox. Int. J. Obes. Relat. Metab. Disord. 28, S66-S71 (2004)

72. Z. Guo, L. Zhou, M.D. Jensen, Acute hyperinsulinemia inhibits intramyocellular triglyceride synthesis in high-fat-fed obese rats. J. Lipid Res. 47, 2640-2646 (2006)

73. Y. Li, S. Xu, X. Zhang, Z. Yi, S. Cichello, Skeletal intramyocellular lipid metabolism and insulin resistance. Biophys. Rep. 1, 90-98 (2015)

74. M.E. Young, B. Leighton, Fuel oxidation in skeletal muscle is increased by nitric oxide/cGMP--evidence for involvement of cGMP-dependent protein kinase. FEBS Lett. 424, 79-83 (1998)

75. M.E. Young, G.K. Radda, B. Leighton, Nitric oxide stimulates glucose transport and metabolism in rat skeletal muscle in vitro. Biochem. J. 322, 223-228 (1997)

76. Y. Higaki, M.F. Hirshman, N. Fujii, L.J. Goodyear, Nitric oxide increases glucose uptake through a mechanism that is distinct from the insulin and contraction pathways in rat skeletal muscle. Diabetes 50, 241-247 (2001)

77. K. Loughney, J. Taylor, V.A. Florio, $3^{\prime}, 5^{\prime}$-cyclic nucleotide phosphodiesterase 11A: localization in human tissues. Int. J. Impot. Res. 17, 320-325 (2005)

78. G. Kakik, N.S. Tuzun, S. Durdagi, Investigation of PDE5/PDE6 and PDE5/PDE11 selective potent tadalafil-like PDE5 inhibitors using combination of molecular modeling approaches, molecular fingerprint-based virtual screening protocols and structure-based pharmacophore development. J. Enzyme Inhib. Med. Chem. 32, 311-330 (2017) 